\title{
Research
}

\section{Biodiversity and Modernization in Four Coffee-producing Villages of Mexico}

\author{
$\underline{\text { Catherine Potvin }}^{1}$, Claire T. Owen, Said Melzi, and $\underline{\text { Pierre Beaucage }}^{2}$
}

\begin{abstract}
Coffee cultivation in Mexico is important both to people's livelihood and to the conservation of plant species richness. Management ranges from traditional shaded coffee garden to "modern" unshaded monoculture. Recognizing the importance of both livelihoods and biodiversity, we examined how the plant diversity of coffee gardens was affected by a certain form of "modernization," which, from 1974 to 1988 , was strongly promoted through the intervention of the Mexican State and international development agencies: that is, planting high-yield varieties (HYV) with little or no shade and using chemical fertilizers and herbicides. Our research also sought to use ecological statistical approaches to understand modifications in a traditional human ecosystem. It centered on two questions: (1) How do differences in coffee production, along a gradient of modernization, affect plant species richness? (2) What is the relative importance of ecological vs. socioeconomic factors in explaining plant diversity in individual coffee gardens? To answer these questions, we compared floristic diversity of four coffee-growing villages differing in ecological context and in the degree to which they were modernized. The two poles of our traditional/modern gradient are the villages of Tierra Colorada, where the traditional Mexican variety of coffee bushes, called café criollo ("creole coffee") is not grown anymore, and San Lorenzo, where all the farms that we studied only grew criollo coffee. Discriminant analysis suggests that modernization can be viewed as a syndrome of traits, among which farmer's education and household size are important components. Overall, the small coffee gardens studied harbor high plant species richness. Our results show a significant negative effect of modernization on plant species richness in San Miguel, one of the four villages studied. Although ecological characteristics were prevalent in explaining species richness, the redundancy analyses (RDA) emphasized the complementary importance of socioeconomic factors in explaining variation in plant species richness in coffee gardens within a given community. Apparently, this importance increases as modernization sets in. In order words, when coffee gardens are managed in a traditional way, as in San Lorenzo, ecological factors are sufficient to explain most variation in species richness. However, in villages where cultivation includes modern practices, these practices exert a direct impact on species richness. The key loading factors for the socioeconomic RDAs were coffee variety, fertilizer, and age of coffee bushes. Our successful methodological approach suggests that numerical ecology offers promising tools for the analysis of human impacted ecosystems.
\end{abstract}

Key Words: coffee farming; ecological and socioeconomic variables; ecological statistics; Mexico; modernization; plant richness; traditional coffee garden.

\section{INTRODUCTION}

Mexico produces one-fifth of the total volume of organic coffee exported worldwide (Moguel and Toledo 1999). It ranks fourth for total volume of coffee produced, fifth for amount of land used for coffee, and ninth for yield performance. Coffee growers are, in the majority, traditional owners working on small holdings ( $<5$ ha.). Many gardens are indigenously owned and operated, with characteristically low yields, little or no use of insecticides or herbicides, and minimal maintenance (Moguel and Toledo 1999). These growers mostly plant the traditional Mexican variety of coffee 
bushes, called café criollo (\&\#8220creole coffee"). The uniqueness of these traditional coffee gardens is that, apart from the main cash crop, they provide various products for their owners, such as firewood, fruits, and medicinal plants, while preserving high biodiversity (Taller de Tradición Oral and Beaucage 1997). Traditional coffee gardens also provide a habitat for numerous plants and animals (Pimentel et al. 1992, Peterson et al. 1993, Perfecto and Snelling 1995, Thiollay 1995, Perfecto et al. 1996, Greenberg et al. 1997a,b, Johnson 2000, Soto-Pinto et al. 2000). They are known to maintain highquality soil while conserving water (Castillo and Toledo 2000).

We examined coffee gardens as dynamic systems responding to both ecological and socioeconomic factors. Between 1970 and 1988, State policy, largely through the Instituto Mexicano del Café (INMECAFE), attempted to modernize the cultivation of coffee (Bandeira et al. submitted). Farmers were induced to replace their traditional, rustic agroecosystems with commercial polycultures or unshaded monocultures, using high-yield varieties (HYV) of coffee that require chemical fertilizers and herbicide (Nestel 1995, Perfecto et al. 1996, Moguel and Toledo 1999). After many good years, the international price of coffee reached a record low in 1990, at the same time that the State withdrew its interventions from the coffee sector, directly affecting modes of production and peasant livelihood (Beaucage 2001). Here, we compare plant species richness in coffee gardens in Tierra Colorada (TC), a Tlapanec village in Eastern Guerrerro; San Lorenzo (SL), a Zapotec village in Oaxaca's Sierra Sur; San Miguel (SM), a Nahua village in Puebla's Sierra Norte; and San Fernando (SF), a Popoluca village in Southern Veracruz (Fig. 1). These four communities differ in their ecological context, with villages on the Pacific slopes (TC and SL) being much drier than the villages on the Gulf of Mexico (SM and SF).

The four villages share many social and cultural traits of Indian communities in Mexico, which translate into a strong sense of both ethnic and community identity, but they differ in agrarian structure, as a result of diverse historical circumstances. In SM, the Nahua faced a process of land privatization in the late 19th century (Beaucage 1995). The small plots were further fragmented through bilateral inheritance, so that most households, nowadays, try to make a living out less than 2 ha of land, usually divided into various plots. The Popoluca community of SF was created when a neighboring hacienda was confiscated after the Revolution (1910-1917) and was transformed into a collective holding (ejido). The family heads informally divided the land among themselves into allotments of about 10 ha each. On the Pacific side, both Tlapanec in TC and Zapotec in SL hold communal titles from colonial times onward, each family keeping its rights to the land as long as they till it. Except in SF, holdings average less than 2 ha each, so there is a strong pressure on land, which leads to emigration and to occasional intercommunity strife.

All four villages grew some criollo coffee bushes before INMECAFE's intervention, but only in SM did farmers have a strong tradition in tilling coffee orchards. Communities also reacted differently to State-induced modernization. During the active years of INMECAFÉ, the Zapotec of SL generally expanded a little their small gardens, without any other adjustment. They retained very traditional gardens, with only criollo coffee under the shade of Inga spp.; they did not use fertilizers or pesticides; and they planted only native timber. In SM, farmers progressively planted the HYV brought in by INMECAFE promoters (Coffea arabica L. var. caturra; C. a. var.mondonovo) in their gardens; then, in view of the good prizes obtained, they substituted coffee to maize (Zea mays L.) in their fields. SF farmers did this from the beginning, whereas in TC, new coffee gardens first replaced sugar cane (Saccharum officinarum L.) as a cash crop and, later, the forest of pine (Pinus spp.) and black oak (Quercus crassifolia Humb. \& Bonpl.) on the steeper hillsides.

These transformations corresponded to a different mode of State interventions. Both SM and SF are located in the main Gulf Coast coffee-growing zone and were exposed to Government pressures and credit offers in the mid-1970s. The more isolated SL and TC occupy much smaller coffee-growing niches on the Pacific side, and were only reached in the early 1980 s by INMECAFÉ. TC's quick enthusiasm depended on a very dynamic marketoriented regional Indian cooperative, Flor de la Montaña, while in the Sierra de Puebla, the spread of monocultivation occurred in spite of the efforts of the regional cooperative, Tosepan Titataniske, which then promoted crop diversification and found market outlets for other local crops such all-spice (Pimenta dioica [L.] Merrill) and sapotilla (Pouteria 
Fig. 1. Regional map indicating the location of the four villages in which the study was performed, as well as yearly rainfall and altitude range at which coffee is grown. TC, Tierra Colorada; SM, San Miguel; SF, San Fernando; and SL, San Lorenzo. The states in which the communities are located are indicated in parentheses.



sapota [Jacq] H.B. Moore \& Stern).

From 1989 on, that is, in the post-INMECAFÉ era, the four villages further adopted different coffee management strategies to face the sudden disappearance of floor prices and subsidies for their crops (Beaucage 2001). San Lorenzo, with the support of MICHIZA, a regional NGO, managed to get into the international market of organic coffee, thus transforming traditional management into "added value." This allowed price stabilization which made small-sized coffee-growing economically sustainable, if not profitable. In a similar way, the SF farmers were induced to diversify their production by a Mexican-Canadian team of researchers. Farmers kept harvesting the existing coffee bushes, but invested minimum labor in maintenance and stopped chemical inputs. They had little success with organic coffee and vanilla (Vanilla planifolia Andr.), but did well with a halfwild palm (Chamaedorea spp.), which is in large demand on the U.S. market. In contrast, in SM, the regional cooperative and State promoters, in order to lower production costs and be profitable in the new free-market conditions, promoted a further modernization of gardens: that is, the complete eradication of criollo bushes, more fertilizers, pesticides, and HYVs that demand full sun 
exposure. Similarly, in TC, the regional cooperative encouraged farmers to increase modernization and facilitated access to fertilizers and pesticides. In both communities, this modernization strategy gave good results during the short period when international prices were high (1993-1997), but proved catastrophic when prices plummeted (from 1998 on).

This documentation of changing coffee production allowed us to examine the relationship between biodiversity and modernization. The four communities reacted in different ways to changing external conditions, yet not all farmers in a given community adopted the same strategy. Two main questions that drove our research are: (1) How do differences in coffee production, along a gradient of modernization, affect plant species richness? (2) What is the relative importance of ecological vs. socioeconomic factors in explaining plant species richness in these coffee gardens?

\section{METHODS}

\section{Study sites and socioeconomic data}

Fieldwork was carried out in the four villages in 1998. All of the villages are situated in a tropical, mountainous environment, but they differ in the prevalent precipitation regime (Fig. 1). Because we were interested in peasant coffee agroecosystems, we only studied small-scale gardens ranging from 0.06 to 2.5 ha. In each village, we sought to work with some 20 households, including families owning "large," (>2 ha), "average," (1-2 ha) and "very small" (<1 ha) gardens; older and younger farmers; and growers of criollo and modern coffee varieties. We relied on snowball sampling to identify potential participants in the study. In all villages, authorization by local authorities and local farmers' organizations was granted after a detailed explanation of the work involved. In Tierra Colorada, 11 households with 27 coffee gardens were studied; in San Lorenzo 17 households with 18 gardens; in San Fernando 16 households with 20 gardens; and in San Miguel, 12 households with 46 gardens. The difference in the number of households/gardens is explained by the fact that, in response to the pattern of fragmented land-owning and to local topographical and ecological constraints, many, if not most, coffee growers had more than one plot planted with coffee. Information on socioeconomic characteristics was obtained by applying a formal questionnaire. Questions asked pertained to farming practices (e.g., use of pesticides, coffee production, and previous use of land), family structure (e.g., numbers and age of household members). The same questions were asked in the four villages, enabling a comparative analysis (see Appendix 1).

\section{Ecological sampling}

Within each garden, sampling of plant species richness was based on a combination of transects and circular plots. We used large $12 \mathrm{~m}$ radius circular plots $\left(452 \mathrm{~m}^{2}\right)$ to sample tree diversity, medium plots ( $3 \mathrm{~m}$ radius) to sample shrubs and saplings, and small plots ( $1 \mathrm{~m}$ radius) to sample herbs. The three circular plots were positioned on the landscape in a concentric way. Triplets of plots (large-medium-small) were located at 250-m intervals along a transect with a second set of medium and small plots positioned $25 \mathrm{~m}$ away from the first set of plots. We fitted as many transects as possible in any given field, transects being at least $300 \mathrm{~m}$ apart to avoid overlap of the large plots. In each of these plots, we recorded presence-absence data of plant morpho-species and scored ecological characteristics. The ecological characteristics were; altitude, slope, soil color, presence of rocks, soil humidity, leaf litter cover, density of herbs, and canopy opening, as well as the presence of moss, lichen, epiphytes, and fern. These characteristics were assessed using an arbitrary, yet easily reproducible, categorical scale (e.g., slope: flat, slight, medium, and steep).

Morpho-species were collected and named using local taxonomy. Researchers worked with a key informant, always the same in a given village, who helped with sampling and identified plants with native names. Usually the farm owner also came in the field (to watch what we were doing!) and confirmed identification. Specimens were collected and pressed. Identification was pursued using Linnean taxonomy in two herbarium collections: one in Mexico City (Escuela Nacional de Antropologia, Laboratorio de Etnobotánica) for the plants obtained from the Pacific Coast (TC and SL), and the other in Xalapa, Veracruz (Instituto de Ecología), for the plants obtained from the Gulf Coast (SM and SF). 


\section{Data analysis}

We used discriminant analysis (Legendre and Legendre 1998) to examine which of the 16 socioeconomic variables (Appendix 1) could best describe agricultural modernization across all four villages. Each plot was classified as "traditional," "intermediate," or "modern," based on the varieties of coffee grown, because it determined the rest of the agricultural practices. If the coffee was criollo, the garden was classified as traditional; if the garden was a mixture of criollo and HYV, the garden was deemed to be intermediate; it was classified as modern if only HYV were grown.

One of our main objectives was to assess the impact of modernization of plant species richness. To answer this question, we proceeded in two steps. First, a principal coordinate analysis (PcoA) was carried out with the entire data set, classifying each field with respect to its ecological characteristics. The PcoA scores for each field were then used as a covariate in the analysis of plant species richness. Total species richness, at the field level, was used as the dependent variable; modernization was the main factor of interest, with its three levels: traditional, intermediate, and modern. Analyses of covariance (ANCOVA) were carried out independently for each village, with the exception of San Lorenzo, where only criollo coffee was grown. Because coffee gardens ranged in elevation from 150 to $15,000 \mathrm{~m}$ a.s.l., a second set of ANCOVAs was performed using altitude as the covariate.

To estimate the flora shared among each pair of villages, we used Jaccard's coefficient of similarity (Magurran 1988). The factors influencing plant species richness were examined using a redundancy analysis, RDA (Legendre and Legendre 1998). For each village, in one set of RDAs we related plant species richness to the ecological characteristics of the sampling plots, while another set of RDAs related diversity to the socioeconomic characteristics of the household. Entries in the plant species richness matrix were the number of species (or genera) in the small, medium, and large plots as well as total species richness in each field. The first explanatory matrix was constructed using ecological characteristics. Categorical variables were therefore coded prior to analysis; a standard coding system was used to make the data comparable over all four villages. A second explanatory matrix was constructed of the socioeconomic data collected at the household level. As in the case of ecological characteristics, most socioeconomic variables, with the exception of age and surface area of gardens, were qualitative and hence were coded (Appendix 1). Different RDAs were carried out for each village.

Because we were interested in the relative importance of ecological vs. socioeconomic variables in explaining variation in species richness, we also performed partial RDAs (Legendre and Legendre 1998:769-779). Partial RDAs allowed us to isolate the direct effect of the ecology on species richness while controlling for socioeconomic factors, and vice versa. All statistical analyses were performed using the program CANOCO, version 4.0 (ter Braak and Šmilauer 1998). For all RDAs, we first included all explanatory variables and used the forward selection option with 199 permutations. Only explanatory variables contributing significantly to the model $(P<0.05)$ were retained and used in a second RDA. Monte Carlo tests (with 999 random permutations) were then performed to evaluate the significance of the canonical axis and to estimate the inter-set correlation.

Table 1. Group means for the socioeconomic variables retained by the discriminant analysis. The groups are (1) modern, (2) traditional, and (3) intermediate coffee plantations, based on the coffee variety grown. Traditional plantations contain only criollo coffee, whereas modern plantations do not contain criollo coffee. Definitions and codes of the socioeconomic factors are in Appendix 1.

\begin{tabular}{lccc}
\hline \hline Variable & $\begin{array}{c}(1) \\
\text { Modern }\end{array}$ & $\begin{array}{c}\text { (2) Traditional (3) Intermed- } \\
\text { iate }\end{array}$ \\
\hline Age & 42.2 & 49.7 & 46.1 \\
People & 4.9 & 6 & 6 \\
Men & 0.9 & 1.7 & 1.5 \\
Children & 2.4 & 2.7 & 2.6 \\
Corn & 0.8 & 1.7 & 1.3 \\
\hline
\end{tabular}

(con'd) 


\begin{tabular}{lccc}
\hline Surface & 2.7 & 1.9 & 1.8 \\
Education & 1.1 & 0.7 & 0.7 \\
Age of coffee & 13.1 & 20.1 & 25.5 \\
Pesticide & 4.2 & 5.7 & 3.4 \\
Shadow & 2.7 & 3.3 & 5.1 \\
Coffee grown & 11.2 & 2 & 9.2 \\
\hline
\end{tabular}

Fig. 2. Classification biplot of the 111 fields studied by discriminant analysis. Fields were classified as modern (1), intermediate (2), or traditional (3), depending on the variety of coffee grown. Each symbol represents one of the sampled fields, and the two axes determine the canonical space of the discriminant analysis. The biplot shows that only two "modern" sites were misclassified by the discriminant functions.

\section{Canonical Scores Plot}

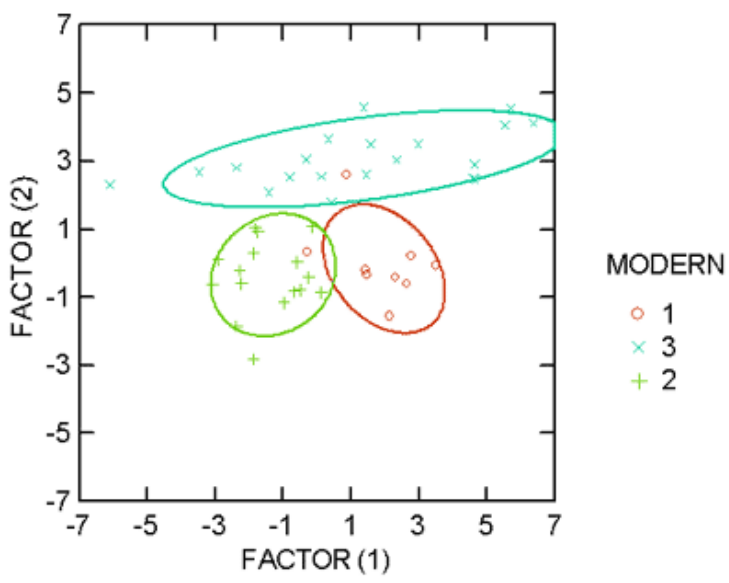

\section{RESULTS}

Discriminant analysis served to identify the suite of socioeconomic characteristics associated with modernization. It also allowed us to verify if classifying gardens on the basis of the variety of coffee grown was a robust approach to describing social changes. The backward elimination procedure of the discriminant analysis retained 11 of the original 16 socioeconomic variables as statistically significant (Table 1). The discriminant biplot illustrates the clear separation in socioeconomic characteristics existing between the three types of coffee gardens (Fig. 2). The variables with the largest contributions to the first canonical axis were: the presence of shadow trees $(-2.549)$, the number of children in the household $(-1.815)$, the number of people in the household (1.737), and the use of pesticides (1.488). The most important loadings on the second canonical axis were: presence of shadow trees $(-1.630)$, variety of coffee grown -1.072$)$, education of family head $(-0.744)$, and use of pesticide (0.652). The classification matrix derived from the discriminant function was able to predict classification into traditional and intermediate gardens with $100 \%$ success, whereas classification as a modern garden was correct $85 \%$ of the time. Thus our working definition of modernization is apparently robust and repeatable.

Our data indicate that local taxonomy was rich, with a total of 714 morpho-species that corresponds to 635 species and/or genera. Overall, we sampled 310 different genera, of which 15 are common to the four villages. Common plant genera were Acalypha, Bidens, Cecropia, Coffea, Desmodium, Diospyros, Ficus, Inga, Ipomea, Mangifera, Mimosa, Musa, Piper, Psidium, and Solanum. Because sampling effort varied among villages, we scaled our analysis to the landscape level (number of species per hectare) and to the garden level (number of species per field). At the landscape level, the highest species richness was estimated for TC (Table 2). Jaccard's coefficient of similarity suggested that the flora of $\mathrm{TC}$ is different from the other floras, whereas the two villages on the Gulf of Mexico share a large number of species (Table 3). Pairwise comparisons of floristic similarity indicated that much of the overlap exists between, on the one hand SF, and on the other hand SM, and SL. Overlap among the four villages was mainly represented by fruit trees (Mangifera indica, Psidium guajava, Salvia sp., and Coffea arabica). 
Table 2. Characteristics of the floristic diversity in the four villages studied in Mexico.

\begin{tabular}{lcccccc}
\hline \hline Village & $\begin{array}{c}\text { No. fields/ } \\
\text { no. plots }\end{array}$ & $\begin{array}{c}\text { Field area } \\
\text { (ha) }\end{array}$ & Morpho-species & $\begin{array}{c}\text { Total no. } \\
\text { species }\end{array}$ & No. spp./ha & $\begin{array}{c}\text { Mean no. } \\
\text { spp./field }\end{array}$ \\
\hline S. Lorenzo & $18 / 120$ & 0.35 & 149 & 86 & 46.3 & $74.8(21.8)$ \\
T. Colorada & $27 / 108$ & n.a. & 234 & 92 & 66.5 & $55.0(20.6)$ \\
S. Miguel & $46 / 184$ & 0.92 & 115 & 85 & 40.9 & $61.9(17.8)$ \\
S. Fernando & $20 / 158$ & 1.10 & 216 & 174 & 48.2 & $128.4(34.7)$ \\
\hline
\end{tabular}

Notes: No. fields/no. plots is a measure of the sampling effort in each village. Field area is the average size of a field in hectares. Morpho-species and total species are estimates of the cumulative richness, following either folk or scientific taxonomy. No. spp./ha represents the average number of species encountered in one hectare and was calculated by dividing the species number in a given field by the surface of that field. Mean no. spp./field represents the average number of species encountered in one field (and $1 \mathrm{SD}$ ).

Table 3. Jaccard's coefficient of similarity for species and genera among the four Mexican villages in this study. Data are entered as percentage similarity for species/and for genera.

\begin{tabular}{llll}
\hline \hline \multicolumn{1}{c}{ T. } & S. & S. & S. \\
& Lorenzo & Fernando & Miguel \\
\hline T. Colorada------ & $4 / 3$ & $1.9 / 8$ & $0.07 / 1.9$ \\
S. Lorenzo & ------ & $2.5 / 18$ & $2.3 / 12$ \\
S. Fernando & & ------ & $5 / 36$ \\
S. Miguel & & & -------- \\
\hline
\end{tabular}

Across all villages, plotting total species richness as a function of modernization levels suggests that plant diversity decreases with the modernization of coffee gardens (Fig. 3). Two sets of ANCOVA were calculated to examine the impact of modernization on plant species richness on a per field basis. The village of SM is the only one in which modernization had a statistically significant effect on plant species richness. The effect of modernization was observed whether PcoA scores $(F=6.8, P<0.003)$ or altitude $(F=6.06, P<0.008)$ were used as covariates. A posteriori comparisons indicate that, in SM, total species richness was significantly higher in traditional gardens $(77.1+/-16.8$ species/field, mean $+/-1 \mathrm{SD})$ than in modern $(54.8+/-17.5$ species/field) or intermediate ones $(58.5+/-15.5$ species/field). The only occasion in which either of the covariates was statistically significant was for TC, where altitude had a significant effect on plant species richness $(F=8.412, P<0.008)$.

For all four communities, RDAs relating ecological variables with species richness were statistically significant (Tables 4-7). The importance of ecological factors in explaining the variation in species richness ranged between $32 \%$ (for SM) and $79 \%$ (for SL). For the two communities located on the Pacific slope (TC and SL), altitude was one of the ecological variables showing the highest correlation with the first canonical axis. The density of herbs and density of ferns were also important (Fig. 4). The RDA biplots indicate that plant species richness tended to increase in coffee gardens at higher altitude. In TC, high species richness was associated with high soil humidity, whereas in SL, species richness was highest in the most shaded plots (Fig. 4). For the communities located on the Eastern coast of Mexico (SM and SF), the most important ecological characteristics were related to the vegetation: cover density of lichens, herbs, and mosses, as well as presence of epiphytes. The more physical characteristics such as soil color and presence of rocks, were not retained as statistically significant.

Socioeconomic factors were statistically significant in three of the four communities, SL being the exception (Tables 4-7). The explanatory power of the socioeconomic RDAs for variation in species 
Fig. 3. Changes in total species richness per field as a function of the three levels of modernization (see Fig. 2) for the four villages under study.

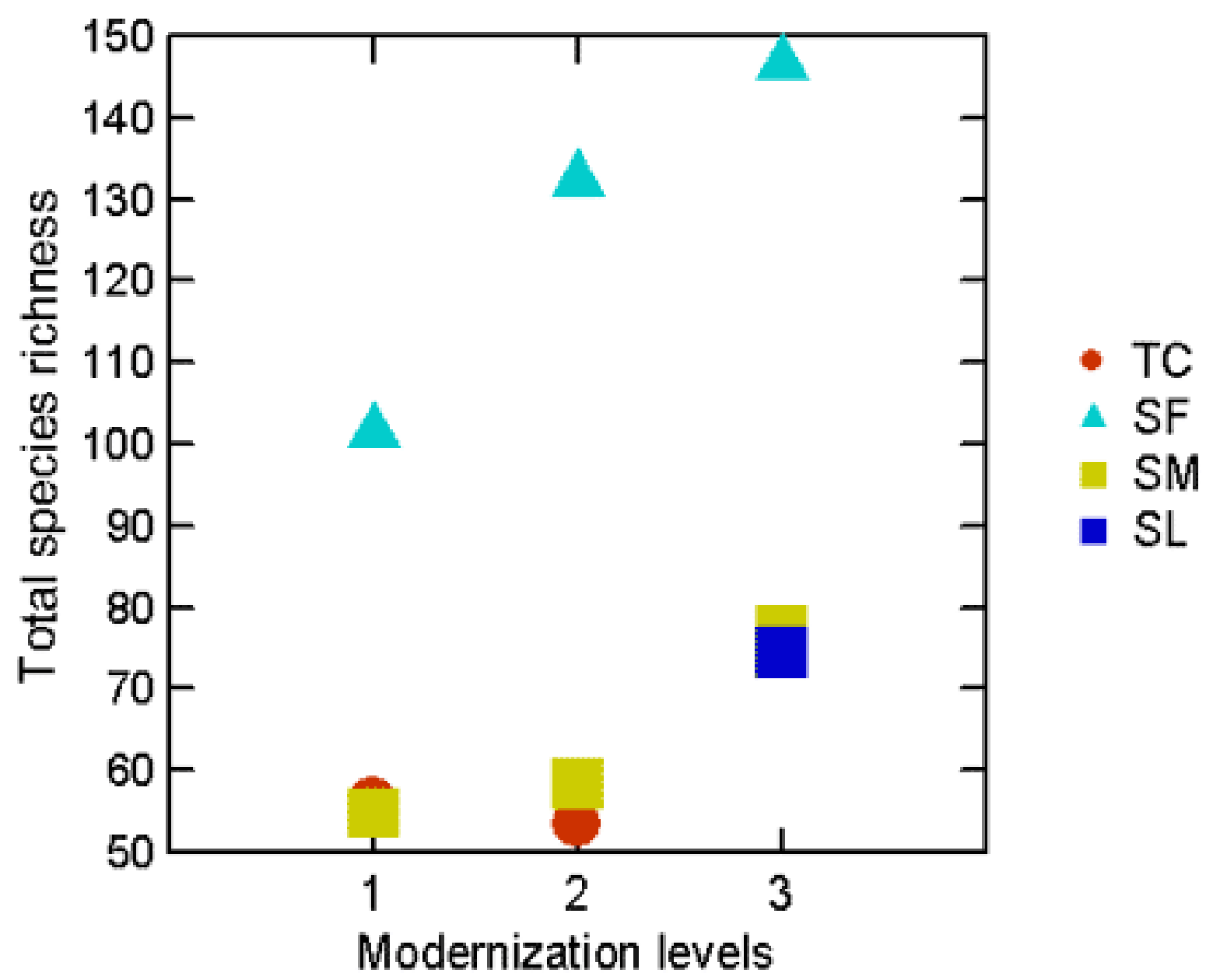

richness ranged from $37 \%$ for $\mathrm{SM}$ to $75 \%$ for $\mathrm{SF}$. In TC, education of the owner and the number of men in the house were the most important loading factors, respectively, for canonical axes 1 and 2 (Fig. 5A). Plant species richness was highest in households where the owner has not received a formal education and where many men were available to work on the land. In SM, the socioeconomic variable with the highest loading on the first canonical axis was the use of fertilizer, whereas the trimming of shadow trees was an important determinant of the second canonical axis.
According to the RDA biplot (Fig. 5B), increased use of fertilizer decreases plant species richness, whereas trimming shadow trees increases it. In SF, the number of people in the house and the age of the garden had the highest loading on the first canonical axis (Fig. 5C). Both variables correspond to an increase in species richness. The second canonical axis was largely determined by the total surface of gardens, and whether or not corn was grown prior to coffee on the same plot.

We further used partial RDAs to partition the 
Fig. 4. Biplots for the ecological variables retained as statistically significant by the RDA for the community of (A) Tierra Colorado, (B) San Lorenzo, (C) San Fernando, and (D) San Miguel. The explanatory variables are in boldface, whereas the dependent variables are in italics.
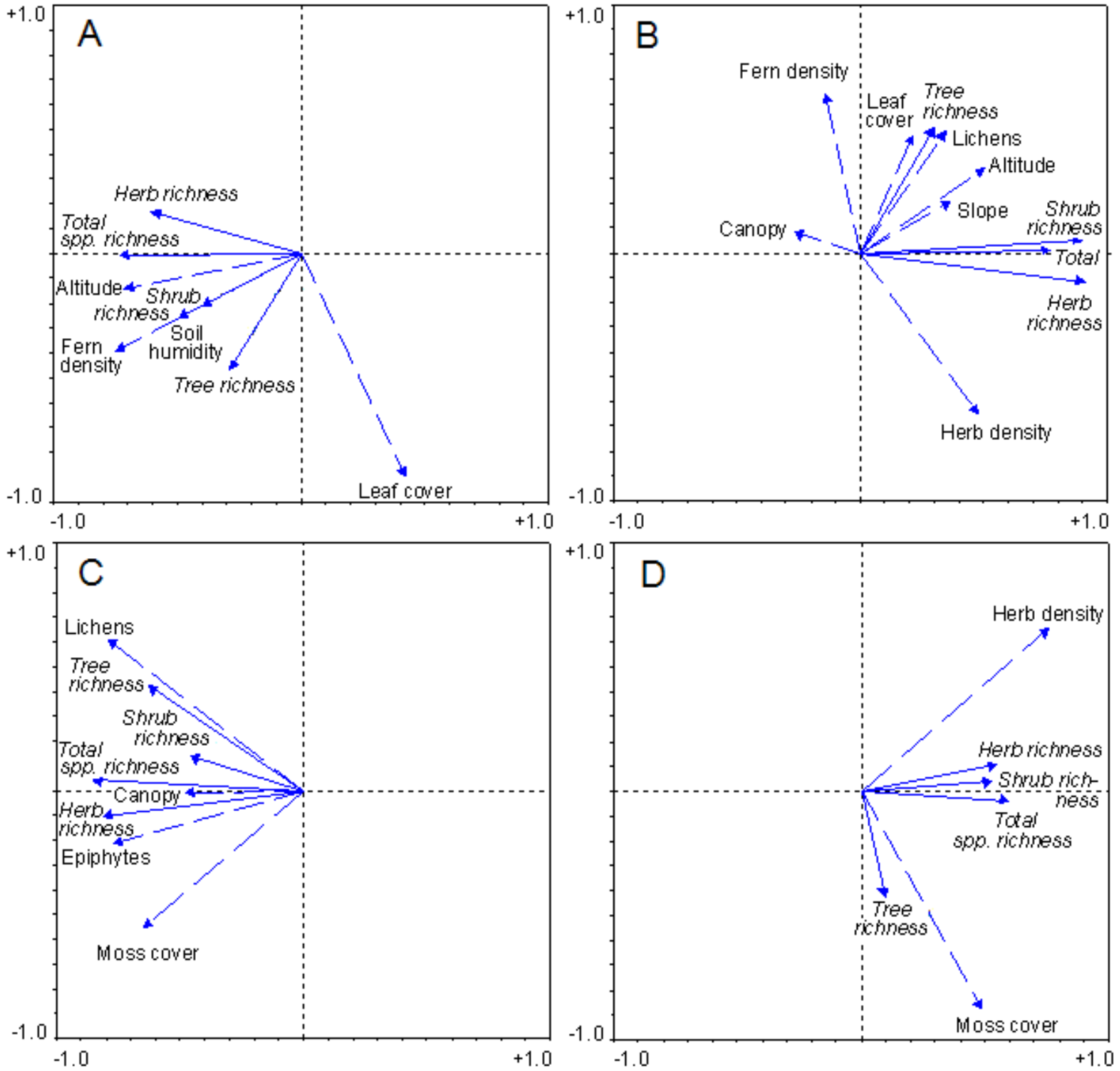

relative importance of ecological and socioeconomic factors on plant species richness. Partial RDAs are derived arithmetically by subtracting different fractions of variation from the total variation (see Table 4). Partial RDAs were only significant for TC and SM (Tables 4-7), and the observed pattern differed for the two communities. In TC, when species richness data were controlled for ecological variation, socioeconomic factors were statistically significant. Isolated socioeconomic factors accounted 
Fig. 5. Biplots for the socioeconomic variables retained as statistically significant by the RDA for the community of (A) Tierra Colorado, (B) San Miguel, and (C) San Fernando. The explanatory variables are in boldface whereas the dependent variables are in italics. Codes for the explanatory variables are presented in Appendix 1.
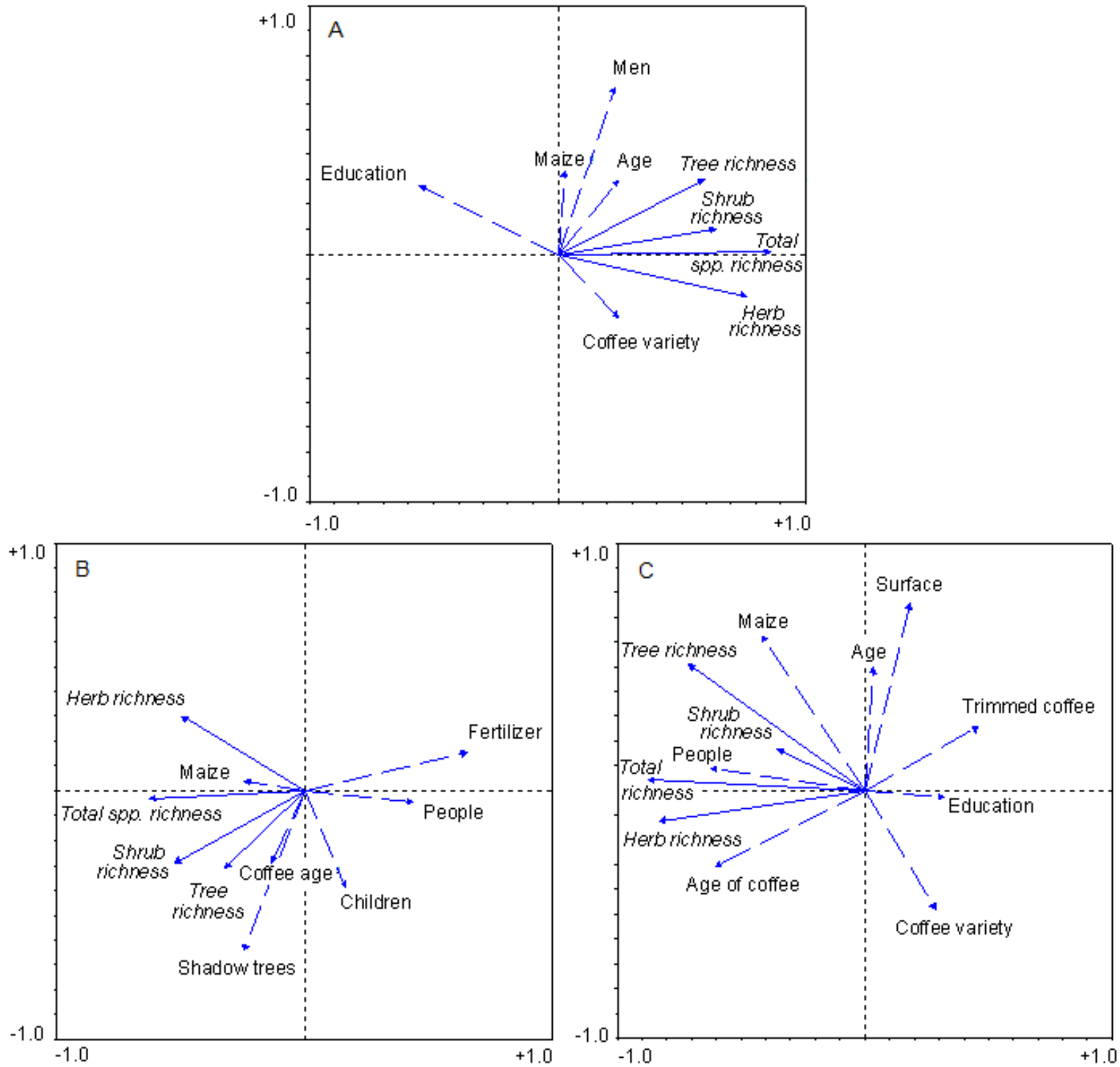
Table 4. Variance partitioning resulting from the partial canonical analyses of ecological and socioeconomical variables on species richness; data are for Tierra Colorada.

\begin{tabular}{lcccc}
\hline \hline Fraction of variation & Proportion of variation & $F$ ratio & df & $P$ \\
\hline Ecological $(a+b)$ & 0.510 & 5.27 & 3,26 & 0.004 \\
Socioeconomical $(b+c)$ & 0.710 & 10.27 & 4,26 & 0.001 \\
Total variation & 0.811 & 8.12 & 9,26 & 0.001 \\
Fraction decomposed & & & & n.s. \\
Ecol. not explained by soc. $(a)$ & 0.101 & 2.27 & 4,17 & 0.01 \\
Soc. explained by ecol. $(b)$ & 0.409 & & & 5,17 \\
Soc. not explained by ecol. $(c)$ & 0.301 & 5.42 & & \\
Unexplained variation $(d)$ & 0.189 & & & \\
\hline
\end{tabular}

Notes: Three RDAs serve as the basis for the present table. The ecological variation $(a+b)$ was obtained by RDA with ecological variables only, whereas the socioeconomical variation $(b+c)$ was obtained by RDA with socioeconomical variables only. Total variation $(a+b+c)$ was obtained by a joined RDA with ecological and socioeconomic variables. The fractions of variations are then decomposed arithmetically to isolate the effect of the strictly ecological and socioeconomical variation.

for $30.1 \%$ of the total variation in species richness observed. Conversely, ecological factors controlled for socioeconomical variation were statistically significant in SM. The isolated ecological factors accounted for $13.1 \%$ of the total variation in species richness.

\section{DISCUSSION}

\section{Ecological statistics, human ecology, and modernization}

As coined by Abel and Stepp (2003), our research was developed as a "conversation between anthropologists and ecologists," recognizing the interrelationship between livelihood and biodiversity. Therefore, we sought to use ecological statistical approaches to understand a system in which "humans and nature interact" (Holling 1998). The use of discriminant analysis allowed us to identify the characteristics of households that engaged in coffee garden modernization. The high classification success rate of the analysis suggests that modernization should be considered as a syndrome of traits. It is more than merely a change in the variety of coffee being planted. This may allow us to understand better what lies behind the blanket term of "modernization"that was so much used during the green Revolution Era. In Mexico, as in many Third-World countries, by "modernizing agriculture," governments and international agencies such as the FAO and the World Bank wanted to achieve three main objectives : (1) to increase agricultural output and productivity, so that farm production could meet increasing domestic needs (households and industry); (2) to transform peasant farming so that it could absorb capital goods, from tractors to pesticides; and (3) to increase the farmers' income, so that they would become part of the new mass consumption market. The cultures of peasants and indigenous peoples were little known and globally considered a hindrance ("backward mentality") that could be neutralized through extension courses and the example of successful modern neighbors. No account was taken of deeply ingrained values and beliefs such as the fact that a Nahua farmer from San Miguel would never pull out a coffee bush which is still giving some fruit ("alive") to replace it by the more 
Table 5. Variance partitioning resulting from the partial canonical analyses of ecological and socioeconomical variables on species richness; data are for San Lorenzo.

\begin{tabular}{lcccc}
\hline \hline Fraction of variation & Propor. of variation & $F$ ratio & df & $P$ \\
\hline Ecological $(a+b)$ & 0.793 & 4.93 & 6,16 & 0.008 \\
Socioeconomical $(b+c)$ & 0.294 & 1.80 & 2,16 & n.s. \\
Total variation & 0.846 & 3.3 & 9,16 & 0.05 \\
Fraction decomposed & & & & n.s. \\
Ecol. not explained by soc. $(a)$ & 0.552 & 3.08 & 7,6 & n.s. \\
Soc. explained by ecol. $(b)$ & 0.241 & & & 3,6 \\
Soc. not explained by ecol. $(c)$ & 0.053 & 0.69 & & \\
Unexplained variation $(d)$ & 0.154 & & & \\
\hline
\end{tabular}

Note: Calculations are explained in Table 4.

productive HYV (called kajfenkonemej "Coffee's children"); this would offend the Father and Mother of Our Sustenance, who live in the Underworld and punish those who throw away their gifts. This explains the rather slow rate of expansion of the new HYV, and not the fact that native farmers "do not understand" the economic advantage of HYV. Similarly, Popoluca farmers in the San Lorenzo area stubbornly refused to plant any crop in horizontal, level rows on the hillsides for "one has to work upwards ." Zapotec of San Lorenzo do not put fertilizer on their coffee bushes because "it makes the Earth capricious and she does not want to give anything afterwards without being fed that way" (P. Beaucage, unpublished data).

Taking into account local values and culture enables us to understand the complex results of 10 years of State-directed modernization policy in the coffee sector. So does the consideration of the peasant family cycle. Across communities, modernization is associated with young farmers, more educated and with smaller households (Table 1). Usually, these younger farmers just inherited or purchased an old, overgrown orchard or a cornfield and government credit would help them to support their families during the growing season. Older farmers, with teenagers to help them with weeding (larger household) and harvesting, found comparatively less advantage to do so. So did the owners of smaller plots, who preferred the varied output of a traditional garden, where one may harvest oranges, bananas, and allspice, and gather firewood year-round (Taller de Tradici-n Oral and Beaucage 1997). On the other hand, farmers who were better off and who had to hire farm hands were likely to adopt the "technology package" (paquete tecnológico): smaller bushes are quicker to harvest and it is cheaper to weed and maintain an orchard with herbicide than with the machete. This is why there was such a wide span of responses to the modernization policy and why one still finds traditional farming and criollo coffee even where regional organization insisted most on modernization, such as San Miguel and Tierra Colorada.

\section{Linking biological diversity to an evolving socioeconomic context}

It has been suggested that changes in modes of production can have a very strong environmental impact (Collins 1984). It is estimated that about $30 \%$ of the coffee regions in Mexico converted from their traditional agroforestry systems to coffee monoculture grown under little to no shade (Nestel 1995). We examined how social changes leading to changes in cultivation practices affected plant 
Table 6. Variance partitioning resulting from the partial canonical analyses of ecological and socioeconomical variables on species richness; data are for San Fernando.

\begin{tabular}{lcccc}
\hline \hline Fraction of variation & Propor. of variation & $F$ ratio & df & $P$ \\
\hline Ecological $(a+b)$ & 0.696 & 8.6 & 3,19 & 0.002 \\
Socioeconomical $(b+c)$ & 0.745 & 4.0 & 7,19 & 0.05 \\
Total variation & 0.860 & 3.6 & 11,19 & 0.04 \\
Fraction decomposed & & & & n.s. \\
Ecol. not explained by soc. $(a)$ & 0.115 & 1.4 & 4,7 & n.s. \\
Soc. explained by ecol. $(b)$ & 0.581 & & & \\
Soc. not explained by ecol. $(c)$ & 0.164 & 1.0 & & \\
Unexplained variation $(d)$ & 0.140 & & & \\
\hline
\end{tabular}

Note: Calculations are explained in Table 4.

diversity in coffee gardens. According to Beaucage (2001), Tierra Colorada and San Miguel are the villages that engaged most in the modernization of coffee gardens. In Tierra Colorada $55.5 \%$ of the gardens that we studied contained solely non-criollo coffee varieties, in contrast with $20 \%$ of the gardens for San Fernando and 17\% for San Miguel. All of the gardens studied in San Lorenzo contained only criollo coffee.

Under the hypothesis that modernization has had an overwhelming negative effect on plant diversity, one would expect plant species richness to follow the gradient: SL > SF > SM > TC. This, however, would only be the case if modernization were to have a more important effect on diversity then environmental factors. This paper therefore examined the relative importance of modernization and environmental characteristics in a variety of ways.

Overall, we identified between 115 and 234 morpho-species (or local taxa) in the coffee gardens of the four villages, a level of diversity higher than the average of 108 species reported by Moguel and Toledo (1999). We estimated that the traditional coffee gardens studied hosted between 41 and 67 species/ha. This compares with an earlier study reporting 35 species/ha in coffee gardens in Chiapas
(Soto-Pinto et al. 2000). Bandeira et al. (submitted), in a survey of 22 small coffee gardens in the province of Oaxaca, reported between 40 and 190 species/ha. Our species richness data are therefore within the range of results reported in the literature. Toledo et al. (2003) have argued that, in Mexico, traditional indigenous management systems are both resilient to changes and successful at maintaining high levels of biodiversity. Our diversity estimates compare favorably with their report, an average of 30 plant species per milpa field, suggesting that traditional coffee gardens indeed harbor a high plant diversity. Furthermore, as suggested in Toledo et al. (2003), traditional coffee gardens are rich in "useful diversity," with important categories of use being edible, ornamental, medicinal, magical-religious, fuel, and shade for coffee.

When data from all four villages were pooled, we observed a trend for plant species richness to decrease with modernization. However, we found a significant negative effect of modernization in only a single community, that of SM. In SM, gardens established only with criollo coffee harbored $25 \%$ more species per field then modern or intermediate gardens. Soto-Pinto et al. (2000), in their analysis of the structure of shade-coffee gardens, emphasized the importance of shade trees in these agroforestry systems. Moguel and Toledo (1999) 
Table 7. Variance partitioning resulting from the partial canonical analyses of ecological and socioeconomical variables on species richness; data are for San Miguel.

\begin{tabular}{lcccc}
\hline \hline Fraction of variation & $\begin{array}{c}\text { Proportion of } \\
\text { variation }\end{array}$ & $F$ ratio & df & $P$ \\
\hline Ecological $(a+b)$ & 0.325 & 10.4 & 1,45 & 0.001 \\
Socioeconomical $(b+c)$ & 0.371 & 3.8 & 5,45 & 0.004 \\
Total variation & 0.502 & 4.7 & 7,45 & 0.001 \\
Fraction decomposed & & & & 0.05 \\
Ecol. not explained by soc. $(a)$ & 0.131 & 4.85 & 2,37 & n.s. \\
Soc. explained by ecol. $(b)$ & 0.194 & & 6,37 & \\
Soc. not explained by ecol. $(c)$ & 0.177 & 2.2 & & \\
Unexplained variation $(d)$ & 0.498 & & & \\
\hline
\end{tabular}

Note: Calculations are explained in Table 4.

calculated that between 23 and 32 tree species were found in an "average" traditional coffee garden. Gardens in SF have an average of 23 species per plot, and those in SL have 13 tree species per plot, yet, according to our definition of modernization, the gardens of SL are more traditional than those of SF. The difference can be related to regional ecology: both SF and SM are located in Neotropical rain forest, whereas SL and TC occupy narrow humid niches in a much drier environment. In SM and TC, there are typically 7.5 and 5.6 tree species per field, respectively. Our data thus suggest that the farms of TC and SM are depauperate in trees vis à vis those of SF and SL. The present results suggest that although the small coffee gardens are speciesrich overall, modernization nevertheless is altering patterns of plant diversity.

Our RDA analyses also unveil that, as modernization sets in, socioeconomic variables become more and more important in explaining plant richness of coffee gardens. In order words, when coffee gardens are managed in a traditional way, as in San Lorenzo, ecological factors are sufficient to explain the variation in species richness. However, as cultivation moves toward modernization, practices such as the use of fertilizers and trimming, or even elimination of, the shadow trees exert a direct impact on species richness.

In closing, we suggest that formal consideration of cultural and socioeconomic variables is needed to understand the functioning of human landscapes. As emphasized by Abel and Stepp (2003), we are just beginning to address human impacts on complex human-ecological systems. Recently, Pereira and da Fonseca (2003) presented a quantitative analysis of biophysical and anthropogenic processes in shaping the diversity of an agro-forestry-pastoral ecosystem, the montado of Portugal. Interestingly, without being aware of their study, we developed a methodological approach very similar to theirs; both studies relied on the used of partial RDAs. As reported for the montado of Portugal, we observed that both ecological and socioeconomic processes were important drivers of plant species richness. We therefore suggest that numerical ecology (sensu Legendre and Legendre 1998) offers promising tools for the analysis of human-impacted ecosystems.

Responses to this article can be read online at: http://www.ecologyandsociety.org/vollo/iss 1/art18/responses/ 


\section{Acknowledgments:}

The research reported here was funded by a CRSHC (Canada) grant to $P$. Beaucage. Collection of ecological field data was completed by: Yann Vergriete (SM), Zabrina Zangen (TC), and Susana Cruz (SF and SL). Questionnaires were passed by Dr Kristin Norget (McGill) and Mauricio Delfin in SL, Pierre Beaucage and Yann Vergriete in SM, Susana Cruz in SF, and Martin Hébert in TC. We are most indebted to the time they spent carrying out the inventories, interviews, and, seemingly endless plant identification.

\section{LITERATURE CITED}

Abel, T., and J. R. Stepp. 2003. A new ecosystems ecology for anthropology. Conservation Ecology 7 (3):12. [online] URL: http://www.consecol.org/vol7/iss3/art12

Bandeira, F. P., C. Martorell, J. A. Meave, and J. Caballero. Floristic heterogeneity in rustic coffee plantations, and its role in the conservation of plant diversity. A case study of the Chinantec region of Oaxaca, Mexico. Submitted.

Beaucage, P. 1995 : Ethnies et société: deux ethnohistoires des Nahuas (Sierra Norte de Puebla). Pages 337-366 in P. Charest and F. Trudel, editors. La construction de l'anthropologie au Québec. En hommage à M.A. Tremblay. Presses de l'Université Laval, Laval, Québec, Canada.

Beaucage, P. 2001. Fragmentation et recomposition des identités autochtones dans quatre communautés des régions caféicoles du Mexique. Recherches Amérindiennes au Québec 31:9-19.

Castillo, A., and V. M. Toledo. 2000. Applying ecology in the third world: the case of Mexico. BioScience 50:66-76.

Collins, J. 1984. The maintenance of peasant coffee production in a Peruvian valley. American Ethnologist 11:413-438.

Greenberg, R., P. Bichier, A. C. Angon, and R. Reitsma. 1997a. Bird populations in shade and sun coffee plantations in Central Guatemala. Conservation Biology 11:448-459.

Greenberg, R., P. Bichier, and J. Sterling. $1997 b$. Bird populations in rustic and planted shade coffee plantations of Eastern Chiapas, Mexico. Biotropica 29:501-514.

Holling, C. S. 1998. Two cultures of ecology. Conservation Ecology 2(2):4. [online] URL:

http://www.consecol.org/vol2/iss2/art4

Johnson, M. D. 2000. Effects of shade-tree species and crop structure on the winter arthropod and bird communities in a Jamaican shade coffee plantation. Biotropica 32:133-145.

Legendre, P., and L. Legendre. 1998. Numerical ecology. Second English edition. Elsevier Science, Oxford, UK.

Magurran, A. E. 1988. Ecological diversity and its measurements. Princeton University Press, Princeton, New Jersey, USA.

Moguel, P., and V. M. Toledo. 1999. Review: Biodiversity in traditional coffee systems of Mexico. Conservation Biology 13:11-21.

Nestel, D. 1995. Coffee in Mexico: international market, agricultural landscape, and ecology. Ecological Economics 15:165-178.

Pereira, P. M., and M. Pires da Fonseca. 2003. Nature vs. nurture: the making of the montado ecosystem. Conservation Ecology 7(3):7. [online] URL:http://www.consecol.org/vol7/iss3/art7

Perfecto, I., and R. Snelling. 1995. Biodiversity and the transformation of a tropical agroecosystem: ants in coffee plantations. Ecological Applications 5:1084-1097.

Perfecto, I., R. A. Rice, R. Greenberg, and M. E. Van der Voort. 1996. Shade coffee: a disappearing refuge for biodiversity. BioScience 46:598-608.

Peterson, A. T., O. A. Flores-Villela, L. S. LeonPaniagua, J. E. Llorente-Bousquets, M. A. LuisMartinez, A. G. Navarro-Siguenza, M. G. TorresChavez, and I. Vargas-Fernandez. 1993. Conservation priorities in Mexico: moving up in the world. Biodiversity Letters 1:33-38. 
Pimentel, D., U. Stachow, D. A. Takacs, H. W. Brubaker, A. R. Dumas, J. J. Meaney, J. A. S. O'Neil, D. E. Onsi, and D. B. Corzilius. 1992. Conserving biological diversity in agricultural/ forestry systems. BioScience 42:354-362.

Soto-Pinto, L., I. Perfecto, J. CastilloHernandez, and J. Caballero-Nieto. 2000. Shade effect on coffee production at the northern Tzeltal zone of the state of Chiapas, Mexico. Agriculture, Ecosystems and Environment 80:61-69.

Taller de Tradición Oral and P. Beaucage. 1997. Integrating innovation: the traditional Nahua coffee-orchard (Sierra Norte de Puebla, Mexico). Journal of Ethnobiology 17:45-67.

ter Braak, C. J. F., and P. Šmilauer. 1998. CANOCO reference manual and user's guide to Canoco for Windows: software for Canonical Community Ordination. Version 4. Microcomputer Power, Ithaca, New York, USA.

Thiollay, J.-M. 1995. The role of traditional agroforests in the conservation of rain forest bird diversity in Sumatra. Conservation Biology 9:335-353.

Toledo, V. M., B. Ortiz-Espejel, L. Cortés, P. Moguel, and M. D. J. Ordoñez. 2003. The multiple use of tropical forests by indigenous peoples in Mexico: a case of adaptive management. Conservation Ecology 7(3):9. [online] URL:

http://www.consecol.org/vol7/iss3/art9 
APPENDIX 1. Standardized definition and codes for socioeconomic variables for the four villages included in this study.

\begin{tabular}{|c|c|c|}
\hline $\begin{array}{l}\text { Socioeconomic } \\
\text { variables }\end{array}$ & Descriptor type & Codes \\
\hline Age & quantitative & age of farmer \\
\hline People & quantitative & number of people living in household \\
\hline Men & quantitative & number of men over the age of 15 living in household \\
\hline Children & quantitative & number of children under the age of 15 living in household \\
\hline Corn & binary & If corn is grown on plantation: $0=$ no, $1=$ yes \\
\hline Surface & quantitative & surface area of plantation in ha. \\
\hline Education & ordinal & education level of farmer: $0=$ none, $1=$ primary, $2=$ primary and secondary \\
\hline Use of field & ordinal & prior use of field: $0=$ none, $1=$ cornfield, $2=$ high bush, $3=$ mix of cornfield and brush \\
\hline Orchard & quantitative & age of coffee orchard \\
\hline Timber & binary & timber being replanted in coffee orchard: $0=$ no, $1=$ yes \\
\hline Shadow & binary & shadow trees being trimmed: $0=$ no, $1=$ yes \\
\hline Coffee trimmed & binary & coffee bushes trimmed: $0=$ no, $1=$ yes \\
\hline Shelled coffee & binary & coffee sold shelled: $0=$ no, $1=$ yes \\
\hline Fertilizer & ordinal & $\begin{array}{l}\text { fertilizer use: } 0=\text { none, } 1=\text { s-simple, } 2=\text { triple abono, } 3=\text { sulfate, } 4=\text { s-simple } \& \text { triple abono, } \\
5=\text { triple abono } \& \text { fertimex } 6=\text { unknown }\end{array}$ \\
\hline Pesticide & ordinal & $\begin{array}{l}\text { pesticides use: } 0=\text { none, } 1=\text { uprocuat } 2=\text { gramazone, } 3=\text { cobre } \& \text { gram., } 4=\text { foley } \& \text { gram., } \\
5=\text { foley } \& \text { paracuat, } 6=\text { karate quimic, } 7=\text { oxicloruro, } 8=\text { bonofolay, } 9=\text { kar. quim. \& oxicl., } \\
10=\text { kar. quim. \& bonof., } 11=\text { kara. quim., oxicl., } \& \text { bonof. } 12=\text { oxicl. \& bonof. }\end{array}$ \\
\hline Coffee grown & ordinal & $\begin{array}{l}\text { types of coffee grown } *: 1=\text { mondonovo, } 2=\text { criollo, } 3=\text { café otro, } 4=\text { mondonovo } \& \text { crio. } \\
5=\text { mondo., crio., \& caturra, } 6=\text { mondo., crio., \& garnica, } 7=\text { mondo., crio., cat., \& garn., } \\
8=\text { mondo., crio., \& otro, } 9=\text { mondo. } \& \text { cat., } 10=\text { mondo., cat., \& garn., } 11=\text { mondo., cat., } \\
\& \text { otro, } 12=\text { mondo. \& borbon, } 13=\text { mondo. } \& \text { otro, } 14=\text { crio. \& cat., } 15=\text { crio., cat. \& otro, } \\
16=\text { crio. \& garn., } 17=\text { crio. \& otro, } 18=\text { cat. \& otro }\end{array}$ \\
\hline
\end{tabular}

* Because only one coffee type was grown in San Lorenzo, criollo coffee was given the code " 1 " in the regional analysis, not " 2 " as shown here. 